\title{
OPINION
}

IN BRIEF

- This lecture describes the impact of six deans of dentistry in Newcastle from 1895-1992.

- Clinical research: perceptions, duration of studies and the link between quality and volume.

- Pressures on the clinical academic career pathway.

- The need for researchers and resources if clinical research is to prosper.

- Changes in oral health 1968-1998.

\section{Founders' and Benefactors' Lecture, March 2003: clinical research - second rate science or basic necessity?}

\author{
Professor J. J. Murray CBE ${ }^{1}$
}

\begin{abstract}
I have chosen to discuss the role of clinical academics in teaching and research, and this will form the main part of my presentation. I want to start however, on an historical note, summarising the impact that former Deans of Dentistry, and some Vice Chancellors, have had on the development of dentistry in the North East. Don't be too worried - I shall be reasonably discreet! Then I will discuss aspects of clinical research before commenting on the resources required for a successful research and teaching programme. In conclusion I will refer to the Adult Dental Health Surveys to demonstrate changes in oral health over the last 30 years.
\end{abstract}

\section{HISTORY}

\section{R. L. Markham}

The first meeting to discuss the formation of a dental hospital in Newcastle was held at the house of Mr R. L. Markham, No. 9 Eldon Square in 1894. Six dental surgeons were present. The dental hospital was officially opened on April 22nd 1895, with $\mathrm{Mr}$ Markham appointed Honorary Dean of the School. He remained in that post until 30 January 1907. One of his colleagues, John Willie Daniels, a co-founder of the Dental Hospital, mischievously suggested that as Mr Markham had 11 children he wanted to reduce the cost of sending them to Edinburgh. ${ }^{1}$ In the event, seven of Markham's sons qualified in dentistry or medicine, or both, at Newcastle (Fig. 1a).

\section{J. T. Jameson}

Mr Jameson, who was born and lived in Bell Villas, Ponteland, acted as Dean from 1907 to 1925. This photograph of Mr Jame-

${ }^{1}$ Emeritus Professor of Child Dental Health, University of Newcastle upon Tyne.

Correspondence to: Professor J. J. Murray, 6 Regency Way, Ponteland, Newcastle upon Tyne NE20 9AU

Email:j.murray@ncl.ac.uk

\section{Refereed Paper}

Received 17.03.03; Accepted 24.03.03

doi:10.1038/sj.bdj.4810274

$\odot$ British Dental Journal 2003; 195: 5-13 son (Fig. 1b) was taken in 1922 when he was President of the British Dental Association. This was one year after the 1921 Dentists Act which regulated, for the first time, the practice of dentistry in this country. He died in 1950, at the age of 87 , and his obituary reported:

'He was an artist in conservative dentistry and some of his fillings and crowns were beautiful work. What he had done for the community of Newcastle was a monument to his industry and love for the profession'

\section{J. Coltman}

Mr Coltman (Fig. 1c) succeeded Mr Jameson as Dean in 1925. Coltman was, like Jameson, an expert in restorative dentistry. During his Deanship, the dental hospital and school was merged with the College of Medicine, moved from the Handyside Arcade (now Eldon Gardens) to a new building on the RVI site. That building still stands today, in front of the multi-storey car park, facing the University Council Chamber. Mr Coltman was a gentle person, who took a great interest in students, but he was no disciplinarian. When the new building was opened there was insufficient money available to buy furniture for the students' common room. The students turned it into a mini rifle range (and we worry about the Med Soc : Dent Soc challenge!). Mr Coltman retired in 1935 and it was decided to appoint a full time Principal, a Director of Dental Studies and SubDean of the Medical School. Professor R V Bradlaw took up his post as Head of Dental School in 1936.

\section{R. V. Bradlaw}

Bradlaw (Fig. 1d) was Dean in Newcastle for 23 years. He instituted a major recruiting campaign, tripling the number of students within a few years, and he masterminded the move from the RVI site to the old medical school buildings in Northumberland Street, opened by Aneurin Bevan in 1948. Mr Bettenson, a former Registrar of the University, referred to Professor Bradlaw's contribution in his History of the University $1834-1977$. $^{2}$

'Perhaps the most dramatic events in the first flush of post-war activity was the way in which dental surgery, under the daemonic (dynamic is an inadequate word) impetus of $R$. V. Bradlaw, was rehoused in the old Medical School and became the largest Dental School in England.'

Robert Bradlaw played a major part in the development of dentistry in Britain. He was instrumental in founding the Faculty 


\section{OPINION}

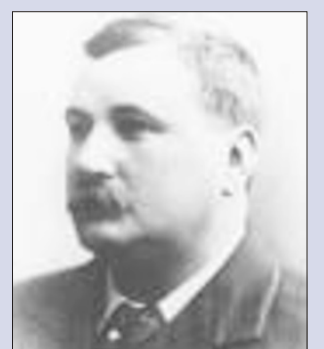

a) R. L. Markham 1895-1907

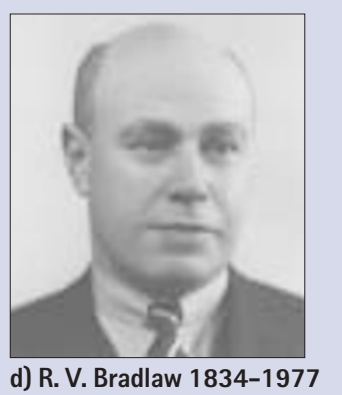

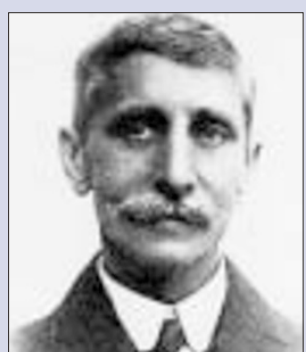

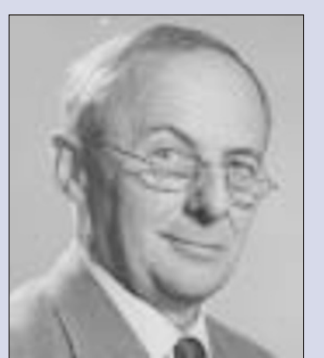

e) G. E. M. Hallett 1945- 1978 b) J. T. Jameson 1907-1925

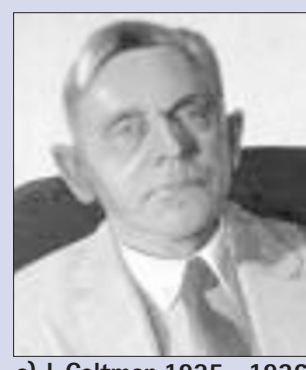

c) J. Coltman 1925 - 1936

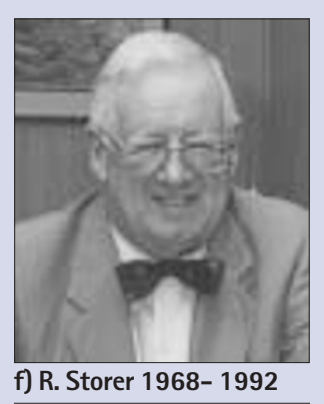

Fig. 1 Deans of dentistry in Newcastle 1895-1992.

of Dental Surgery at the Royal College of Surgeons of England in 1948, left Newcastle in 1959 to become Dean of the Institute of Dental Surgery and Director of the Eastman Dental Hospital in London, and served for ten years as President of the General Dental Council. He was Knighted in the early 1960s and was awarded a Doctorate of Civil Liberties at an Honorary Degree Ceremony in the King's Hall in May 1965. The Public Orator, Dr Henry Miller, introduced him to the Chancellor with the following words:

'Sir Robert Bradlaw needs no introduction to Newcastle, nor Newcastle to Sir Robert. In the medical as well as the dental sphere our City and University are only slowly regaining the placidity which preceded his twenty-three year assault on their virtue. He set the Tyne on fire in no uncertain manner, and when he left us in 1959 he had been instrumental as its Dean in establishing the Newcastle Dental School as one of the largest and most important in the English-speaking world. Personally instituting the drift to the south, he left us to take up a similar but of course less important post in the metropolis. During a life of frenzied professional activity, honours and appointments have rained on him. We must regretfully admit that some of the most important have been acquired since he severed his connection with us, and we can only trust this is not an instance of cause and effect. They have come from every civilised country in the world, and also from one or two others.....'

Robert Bradlaw achieved great national and international recognition. His heart was always in Newcastle. When he died in the early 1990s he left his estate to the university for the good of the sub-faculty of dentistry. We have used the interest on his capital to provide $\mathrm{PhD}$ studentships to improve our research profile. In 1999 $£ 250,000$ of his capital helped to provide a new dental clinical skills laboratory.

\section{G. E. M. Hallett}

Mr G. E. M. Hallett (Fig. 1e) was appointed to a lectureship in child dentistry in 1945. He was promoted to Reader and then Professor of Children's Dentistry in 1951, the first chair in this discipline in the country, and one which I succeeded to in 1977. On Bradlaw's resignation, Professor Hallett was appointed Dean and immediately had to face some of the problems left by Bradlaw's 'dash for growth' policy. The General Dental Council visitation in 1961 was forthright in its condemnation of the poor facilities and inadequate staff-student ratio. The Rector of King's College, Dr Bosanquet was aware of the problems facing both medical and dental education. He, together with a small group of senior officers of the University, had the vision to plan 'a new dental school and hospital, in close association with the new medical school on land belonging to the Governors of the United Newcastle Hospitals. The new Medical School, Dental School and Hospital complex will be developed in such a way as to form with King's College a single large educational and hospital precinct.'

It was this vision to develop one of the most integrated medico-dental university hospitals in Europe, which dominated Hallett's life for the next 17 years. Of all the pictures I have seen and personal memories I have of Maurice Hallett, one remains the clearest in my mind. It is the photograph of him driving a bulldozer to cut the first turf to start the process of building (Fig. 2). In his Christmas letter of 1974 he wrote:

'This letter marks a milestone in the history of the Dental School and Hospital. At last I can report, positively, that work has started. I was, officially, invited to drive an earth-moving machine to the great peril of myself and other colleagues who were there and this cut some of the first turf on the new site on Wednesday 19 May.'

Witnesses who were there at the time have assured me that nothing would have stopped Maurice Hallett from driving that bulldozer.

Thus the first phase of the medico-dental complex, a vision shared by Bosanquet and colleagues in the late 1950s, began to take shape. Professor Hallett retired in September 1977 and was not able to see the official opening of the new Dental School and Hospital during his Deanship, although he was present at the official opening on 15 September 1978.

\section{R. Storer}

Professor Roy Storer (Fig. 1f) came from Liverpool to a Chair in Prosthodontics in 1968. He succeeded Hallett as Dean in 1977. What was Storer's legacy?

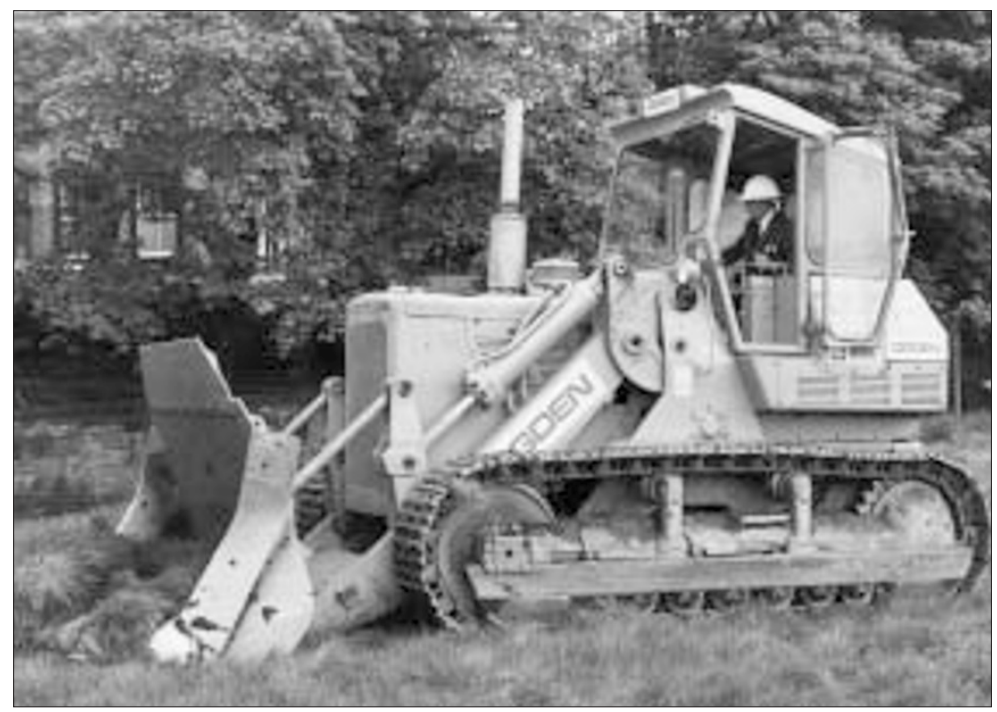

Fig. 2 Professor Hallett cutting the first turf on the new site for the Newcastle Dental Hospital and School, May 1974. 
Nineteen colleagues, appointed between 1977 and 1992 in post in 2001, bore a major responsibility of developing teaching and research in the Dental School. If they had not been appointed then it is most unlikely that we would have performed so well in the Teaching and the Research Assessment Exercise in 1999 and 2001. Oral Biology has prospered in Newcastle since the appointment of Howard Tonge and Neil Jenkins in the 1940s, John Eastoe in 1980 and Roy Russell in 1991. Dental materials science has developed because of the tremendous efforts of John McCabe. I acknowledge their contribution and collaboration, but it is the subject of clinical research that I now wish to discuss.

\section{CLINICAL RESEARCH}

I want to address three issues

- Perceptions of clinical research

- Duration of studies

- The relationship between quality and volume

\section{Perceptions of clinical research}

I remember my early days as a Research Fellow, supervised by Professor Douglas Jackson at Leeds University. He was greatly influenced by a brilliant physicist and physiologist and head of the MRC Environmental Research Unit, Professor Philip Burch. Burch's work was based on Sir MacFarlane Burnett's 'Forbidden clone' theory, for which he received the Nobel Prize for Medicine in the 1960s. Burnet stated that 'If the form of age incidence of a disease is reproducibly similar in different environments, this must be regarded as one of its characteristics and therefore calls for its interpretation. Burch developed this theory and, together with Jackson, propounded new hypotheses for the aetiology of dental caries and periodontal disease. ${ }^{3}$ The diagrams they published looked impressive. In the text, the terms 'stochastic curves', 'random events', 'latent period' and 'forbidden clone theory' had the flavour of international research. Philip Burch contributed two pages to the discussion section of my own PhD thesis, which I gained in 1970.

In contrast, the topic of oral hygiene instruction in children using manual and electric toothbrushes appears mundane. This may be one reason why our first paper on the subject was rejected. On hearing of the rejection, Colin Davies, then head of Gibbs Oral Hygiene Service, which had kindly supplied toothpaste and brushes for the study, suggested that if the work had been carried out in the laboratory on a small sample of castrated albino rats the paper might have been more readily accepted! Work on the topic continued and a new paper was submitted and published in 1976. After writing to thank him, Colin Davies

\begin{tabular}{|c|c|c|}
\hline & Females & Males \\
\hline Beaker $<1$ per day & 7.5 & 8.0 \\
\hline Non-beaker $=2$ per day & 5.1 & 5.2 \\
\hline
\end{tabular}

replied on a postcard, 'The Lord works in mysterious ways, His wonders to perform'

One study which would have considerable impact on the dental health of children was carried out in Glasgow by Chesters and colleagues. They compared different methods of rinsing the mouth after tooth brushing and concluded that 'using the hand' was more effective in terms of caries inhibition than using a brush or a beaker. They also showed that brushing once a day or less was worse than brushing twice per day. Combining both these aspects resulted in a marked effect on caries increment (Table 1). Rinsing method and brushing frequency are not obviously high profile and may not appear appropriate for funding applications to research councils, but taken together, these two methods could save one DFS surface per child per year. Surely this is a health gain worth fighting for. Now, a paper on oral hygiene may not be rated as highly as the research by Burch and Jackson, which would almost certainly have been judged of international standard if an RAE panel had been in place in the 1960s. But the Burch Jackson hypothesis was wrong. Sometimes 'pure' research seems to be more exciting and is often given a higher rating than clinical research.

In 1967 I was sent to Hartlepool to examine 5,000 children and adults. I was also told to read this book - Moroney, Facts from figures. One of the diagrams in that book refers to the $\chi^{2}$ test which Moroney says is one of the most fundamental distributions in statistics (Fig. 3). Most of us focus on the left hand side of the diagram, looking for values that would be significant at the $5 \%$ or $0.1 \%$ level of possibility, but Moroney suggested that one should also look at the other end of the distribution, the 95\% - 99\%. He called these the lines of 'suspiciously good fit'. Although I read these words over 35 years ago the phrase 'line of suspiciously good fit' ${ }^{4}$ has always remained with me and is one of the feelings that any clinical researcher should have. There are too many short-term studies that are almost too good to be true that turn out not to benefit patients in the long term. As clinicians we should always be sceptical as well as ready to embrace new treatments and technologies. A pure scientist can repeat experiments, reduce variables, remove impurities, but a clinical researcher has to deal with the vagaries of human variability.

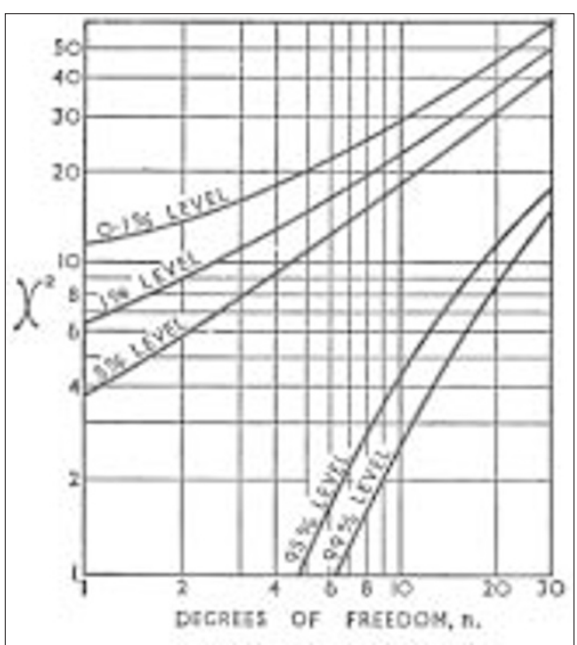

Fig. 3 The Chi-squared distribution (from Moroney ${ }^{4}$

What were you doing on the 11 September 2001? Can you remember where you were when news came in of the dreadful assault on the twin towers in New York? Leslie Robertson was the structural engineer who built the World Trade Centre (Fig. 4). ${ }^{5}$ He had obviously agonised over his construction which began in 1971 to see if there was anything he could have done that would have prevented that awful tragedy. He said 'I' $m$ sort of a methodical person, so I listed all the bad things that could happen to a building and tried to design for them.' He actually designed the buildings so they would be able to absorb the impact of a jet airliner because he knew of the Air Force bomber lost in the fog that hit the Empire State Building in 1945. The 707 was the state-of-the-art airplane then and they studied it and designed for the impact of such an aircraft. However on 11 September each building took the impact of a 767 which is nearly 20\% heavier than a 707 . Robertson said as he looked out over ground zero 'It is a tremendous responsibility being an engineer, it is a very imperfect process. It is not so beautiful as science.' I had great sympathy with these words. I think that is a very good analogy with the difficulties of good clinical research and the problems that face clinical researchers.

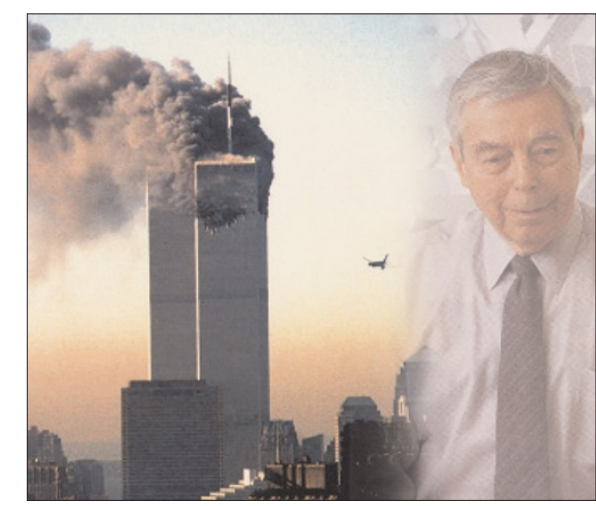

Fig. 4 Lesley Robertson, Structural Engineer of the World Trade Center. 


\section{OPINION}

\section{Duration of studies}

It is sometimes difficult to convince colleagues in non-clinical disciplines of the length of time that clinical studies must be continued, in order to produce a meaningful result. Let me give you two examples. The first is from the recent review of water fluoridation by the NHS Centre for Reviews and Dissemination in York. ${ }^{6}$ Many buzzwords are used - 'systematic review, predefined hierarchy of evidence, objective specific inclusion criteria. To locate, appraise and synthesize evidence from scientific studies in order to provide informative empirical answers to scientific research questions.'

These illustrations are taken from the York study (Figs 5, 6 and 7) and show that, whilst there is no evidence that fluoride in drinking water has any effect on bone fractures it does have an impact on dental caries. Furthermore, when water fluoridation ceases, most of the studies included show a deterioration in that caries experience increases.

The first artificial fluoridation study began in Grand Rapids in 1945 (Figure 8). This is a simple diagram, but makes some important points. First, caries in Grand Rapids was high before fluoridation started. Second, caries rates after fluoridation were very similar to that found in the natural fluoride area of Aurora Illinois which had $1.4 \mathrm{ppmF}$ in the water. But the third point is the duration of the study: the graph shows the dates 1944, 1954 and 1959. It took 15 years to compile the date on that graph. This study was published in $1962 .{ }^{7}$

The second piece of work I want to mention concerns the durability of restorations in primary molar teeth carried out in the Department of Child Dental Health here in Newcastle. For many years we have carried out studies where pairs of cavities in primary molar teeth are restored with different materials. Our first study compared amalgams with glass ionomer cement. We showed that the amalgam restorations lasted a little longer than for glass ionomers but that restorations with glass ionomers cements were smaller and required the removal of much less tooth tissue. ${ }^{8}$

A picture of a six-year-old child is given in Figure 9. He took part in one of our studies and apparently has a nice set of teeth, although a dentist would be concerned about the black mark on the mesial side of the front tooth. A palatal view shows something of rather greater concern (Fig. 9a). The teeth are very shiny; they have suffered erosion from the consumption of fizzy drinks. His posterior teeth were very decayed and filled with a modern adhesive restorative material (Fig 9b). Even the restoration has suffered erosion, showing that the mouth is a hostile environment. But the restoration

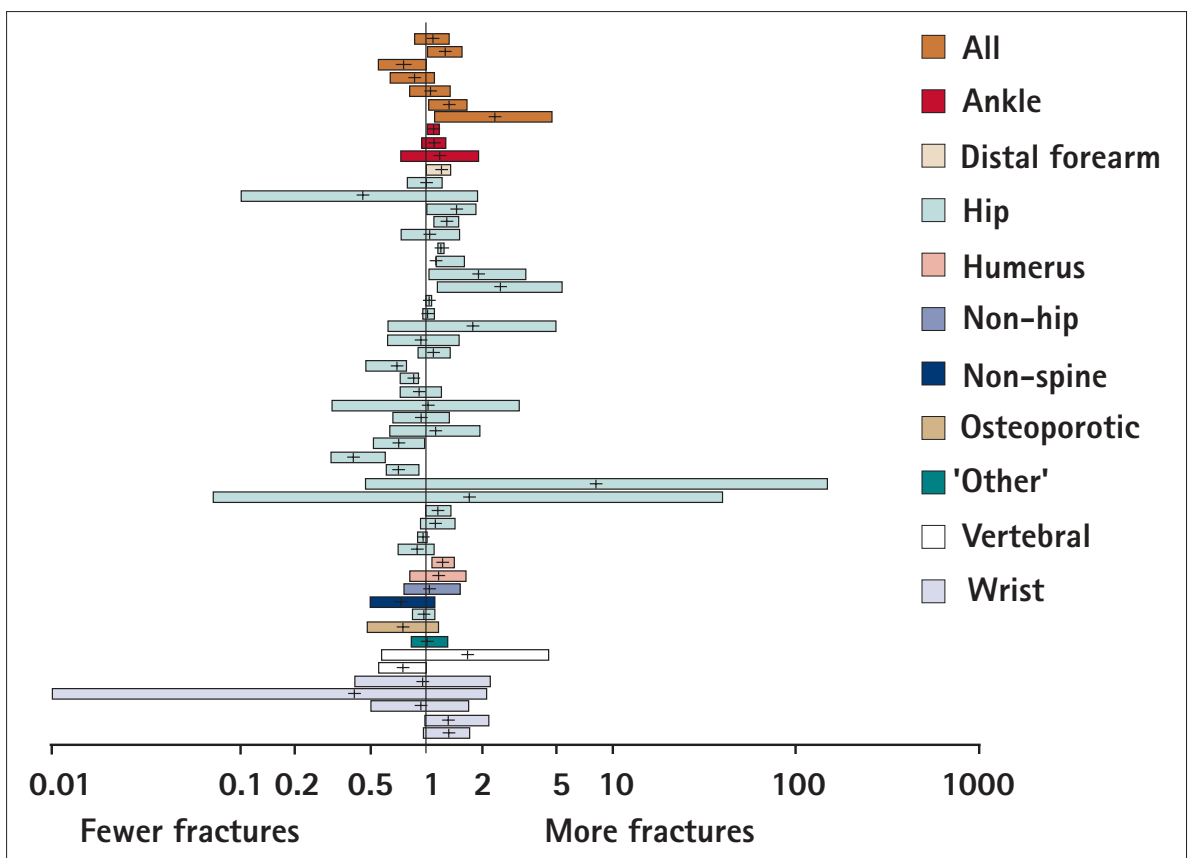

Fig. 5 Bone fracture incidence (measure of effect estimate and $96 \% \mathrm{CI}$ ). The majority of the measures of effect and their confidence intervals were distributed around 1, the line of no effect, suggesting no association. Reproduced with permission from the NHS Centre for Reviews and Dissemination.

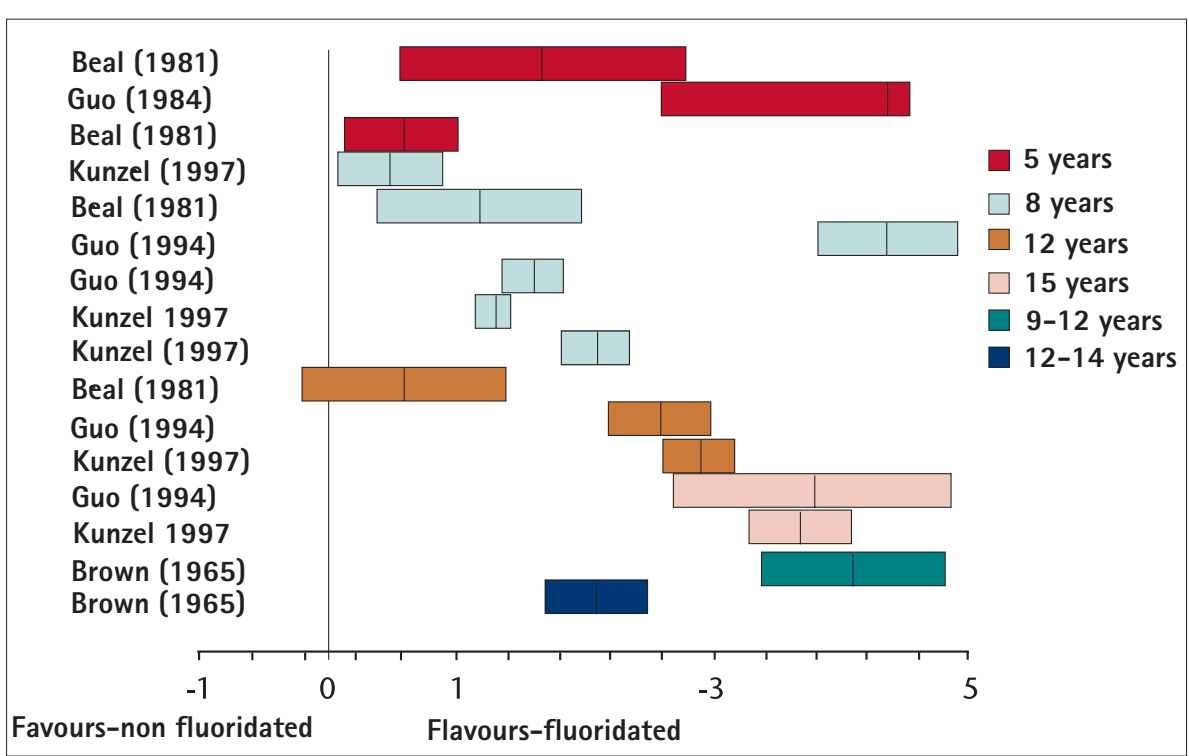

Fig. 6 Change in dmft/DMFT score (mean difference and 95\% C I). Fifteen studies found a statistically significantly greater mean change in $\mathrm{dmft} / \mathrm{DMFT}$ scores in the fluoridated areas than the non-fluoridated areas. Reproduced with permission from the NHS Centre for Reviews and Dissemination.

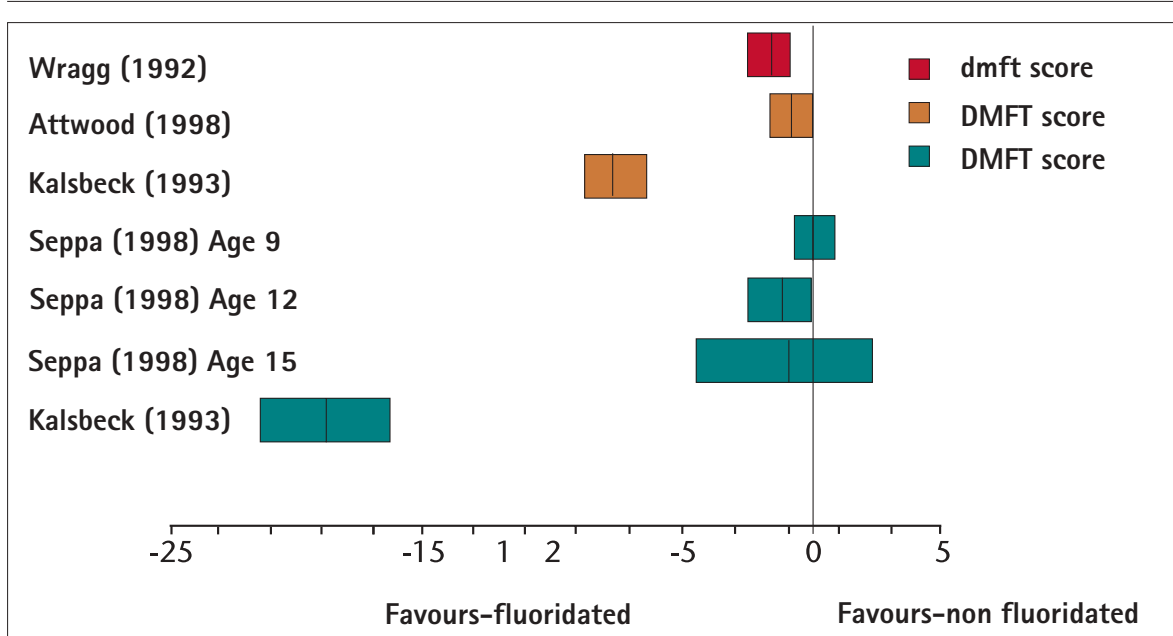

Fig. 7 Stopping fluoridation: dmft/DMFT on DMFS score (mean difference and 95\% CI). Reproduced with permission from the NHS Centre for Reviews and Dissemination. 
has remained in situ. That baby tooth should exfoliate, or fall out, when the child is nine or ten years of age, so all we need of that restoration is that it lasts another two or three years and then a permanent premolar tooth will erupt. We must use that time to change the diet and introduce preventive measures. By preventing pain and a possible extraction now, we have a better chance of ensuring that the permanent teeth will not suffer the same fate as his primary teeth, and then he will keep his teeth for life.

These new adhesive materials do not need so much tooth preparation, and are usually easier for young children to cope with. Our latest study compared glass ionomer with Dyract, a compomer which was light cured. The results showed that Dyract was superior to glass ionomers cement. When we put the results of all the previous studies together, we were able to show that Dyract was at least equal to amalgam in terms of durability. ${ }^{9}$ The clinical work involved in producing the data in this slide took 17 years to complete; from 1982 to 1999 , just in time for the last RAE (Fig. 10).

\section{Quality and volume}

The link between quality and volume can be illustrated in the following diagram: quality is portrayed on the horizontal axis and volume on the vertical axis (Fig. 11). Please do not think that volume alone ensures quality. In fact the worst case scenario is high volume, low quality: we have had too many examples recently. First: Harold Shipman, over 200 patients murdered. Would the Bristol Heart Surgery scandal have been brought to light if a smaller number of babies had died following surgery? The sight of 29 small white coffins in front of the General Medical Council was a very powerful message that something was wrong.

I want to pursue this link between volume and quality by referring to the Clinical Standards Advisory Group enquiry into the management of cleft lip and/or palate which I chaired. The Clinical Standards Advisory Group was set up in 1990 by an Act of Parliament. Its membership consisted of:

- Those nominated by the medical, nursing and dental Royal Colleges and their Faculties

- Chairmen of Standing Medical, Nursing and Midwifery, and Dental Advisory Committees

- Representatives of Professions Allied to Medicine.

I was appointed Chairman of the Standing Dental Advisory Committee in 1992 and so was nominated onto CSAG. One of the concerns that orthodontists raised at the Standing Dental Advisory Committee was the quality of outcome of patients with cleft lip and/or palate. CSAG were persuad-

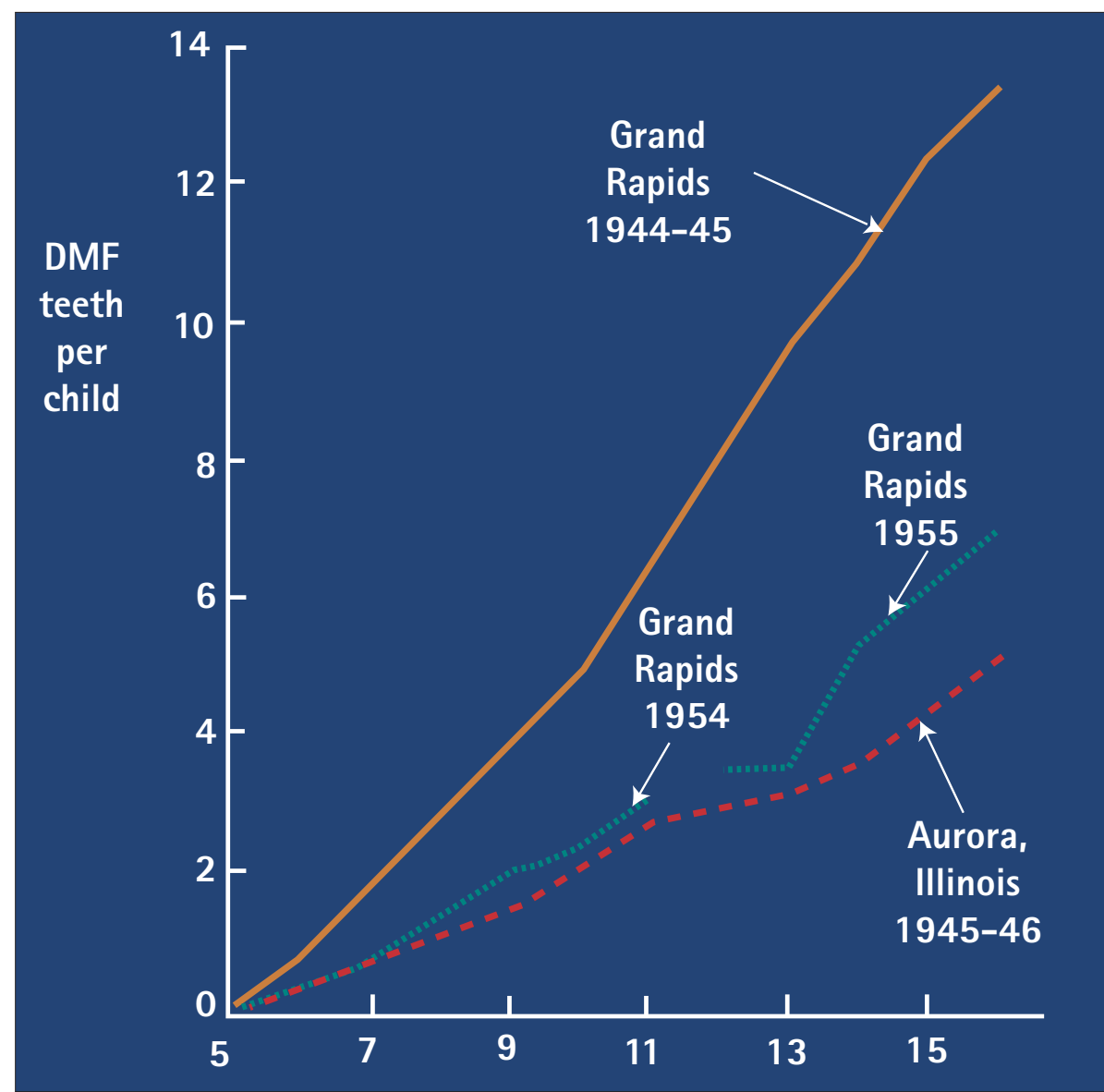

Fig. 8 Fifteen years of fluoridation in Grand Rapids (Arnold et al. 1962).

ed that the management of cleft lip/palate was multi-disciplinary, and that although there were fewer than 1,000 cases a year, an investigation might act as a model for other rare conditions. We were given less than two years to complete the study:

July 1995 Remit agreed by UK Health Committee

Sept. 1995 Committee appointed

Nov. 1995 Research team appointed

Feb. 1996 Pre-pilot study

Mar. 1996 Fieldwork started

Oct. 1996 Visits arranged

Mar. 1997 Draft report submitted to CSAG

June 1997 Report accepted by CSAG

Aug. 1997 Report submitted to Secretary of State

The researchers, travelled the country to visit all the centres in the UK. I was responsible, with the committee, for writing the report. ${ }^{10}$ I want to show you just two sets of results. First, skeletal relationship in 12year-old children - as measured by lateral skull radiographs (Table 2 ).

Table 2 Skeletal relationship in 12-year-old children who have unilateral cleft lip and palate (205 lateral cephalostats).

Skeletal I 17\%

Skeletal II $\quad 13 \%$

Skeletal III

$70 \%$

CSAG Report 1998
Then the treatment outcome for 12- yearolds who have unilateral cleft lip and palate; assessed independently by studying the impressions taken of every child (Table 3 ).

The Goslon index - a play on the words Great Ormond Street, Oslo and London, has five divisions. Goslon 4 and 5 represent a poor arch relationship - Class

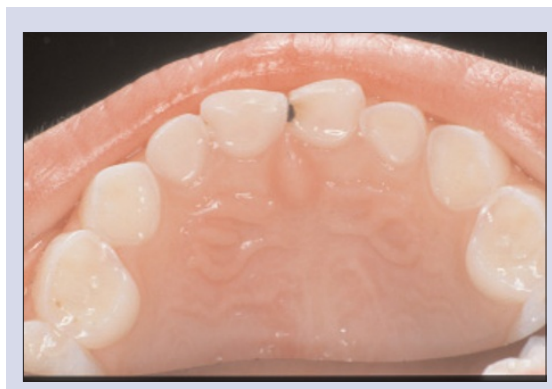

Fig. 9a Palatal view of the upper arch of a 6year-old child affected by caries and erosion.

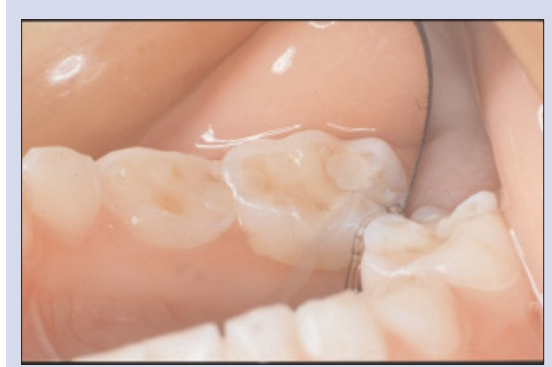

Fig. $9 \mathrm{~b}$ View of posterior teeth of same child. 


\section{OPINION}

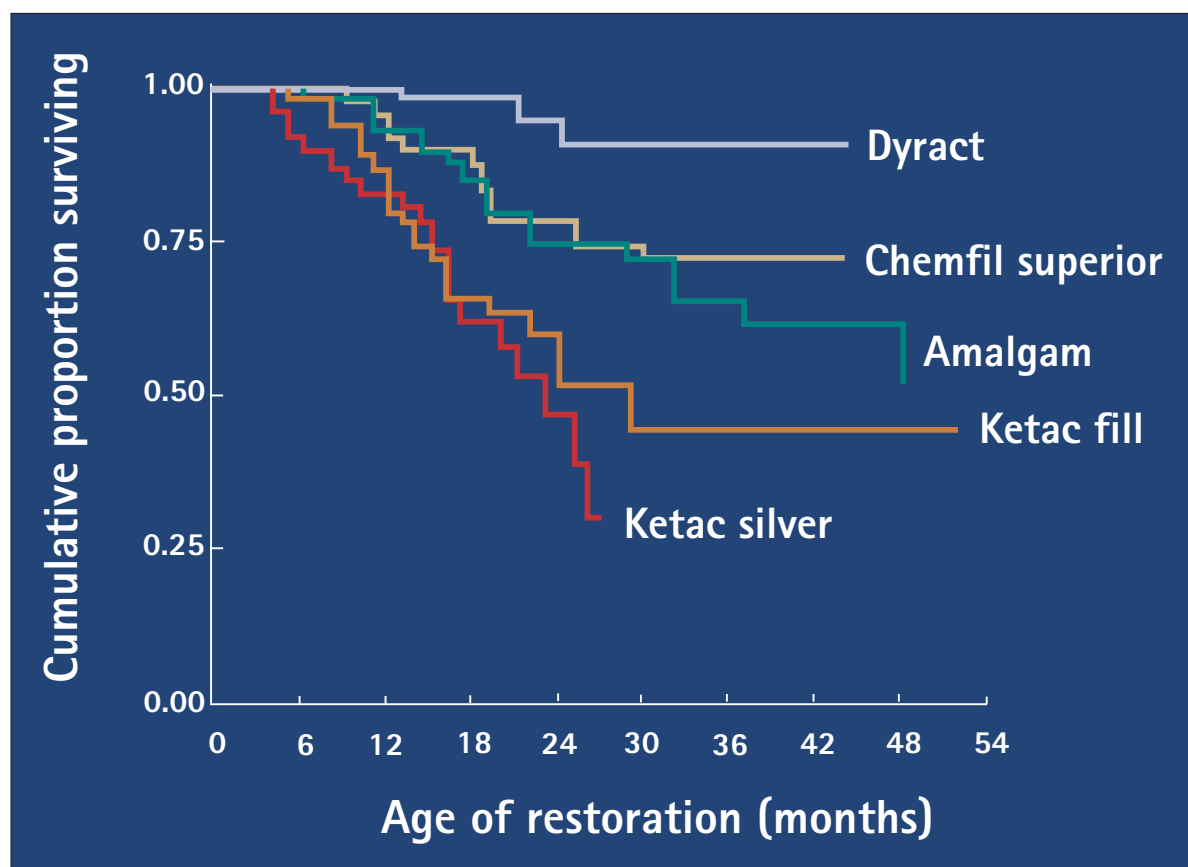

Fig. 10 Survival curves for restoration in primary molar teeth (Welbury et al. 2000).

III malocclusion where an osteotomy will probably be needed to improve appearance. The results are clear. Britain lags far behind three European centres which concentrate their patients into a centralized

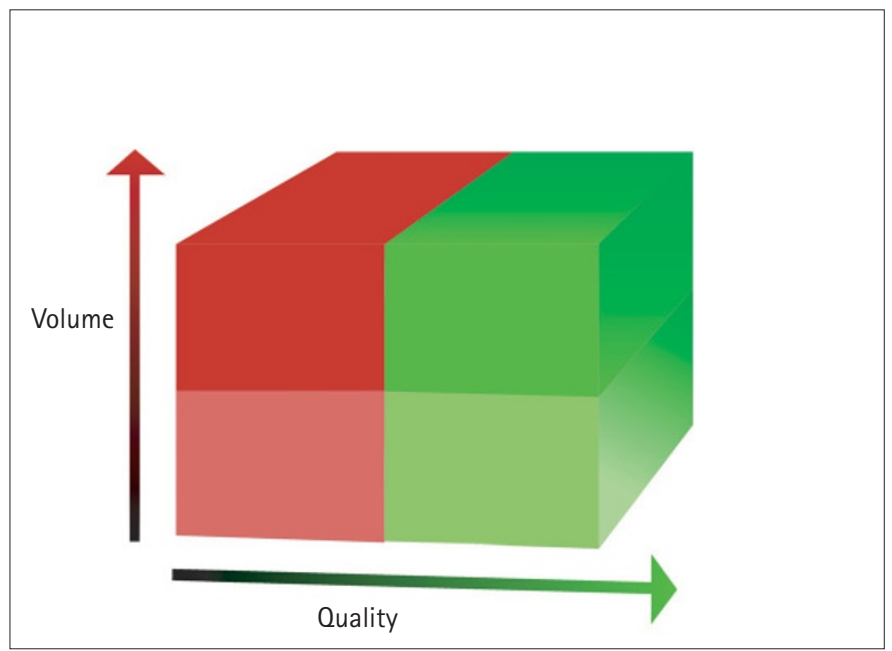

Fig. 11 Diagram illustrating the link between quality and volume.

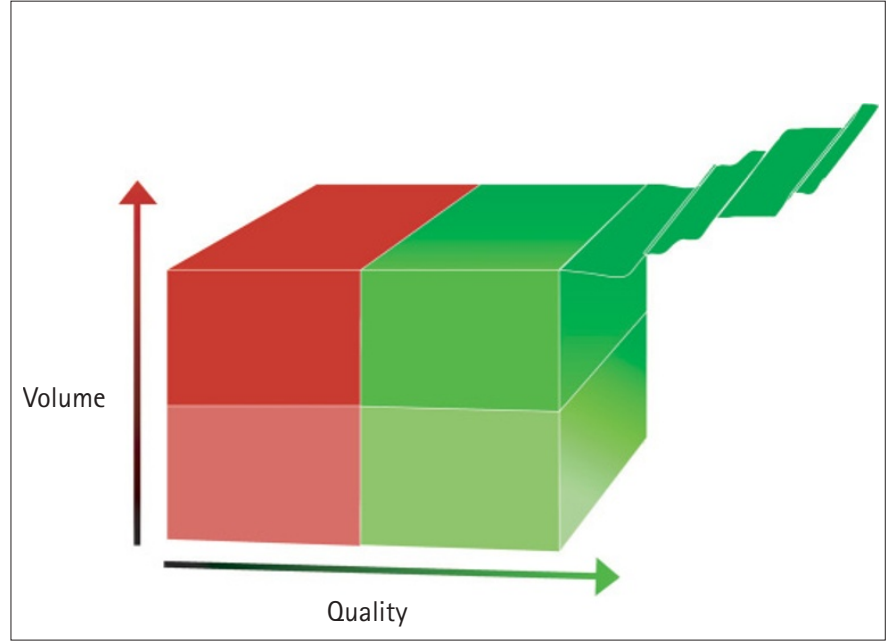

Table 3 Treatment outcomes for 12-year-old children who have unilateral cleft lip and palate. \begin{tabular}{rlll}
\hline CSAG Euro 1 & Euro 2 & Euro 3 \\
\hline
\end{tabular}

$\begin{array}{lllll}\text { Proportion (\%) } & 39 & 4 & 8 & 7\end{array}$

with poor arch

relationship

(GOSLON 4 \& 5)

CSAG Report 1988

lateral complete cleft of lip and palate per year.

All nine of our recommendations were accepted by the Government in February 1998. The first and most important was as follows:

CSAG recommendation

'The UK Health Departments should ensure that the present arrangements involving 57 cleft units are changed so that expertise and resources are concentrated in 8-15 centres in the UK taking into account population needs and accessibility.'

The government set up national and regional implementation groups to achieve this concentration into specialist centres. Although some progress has been achieved, much more needs to be done to ensure quality services for babies born with cleft lip/palate in this country.

The need to concentrate expertise in any discipline is supported by the comments by Professor McVie, Head of Cancer UK on the surgical management of cancer. 'Study after study has shown that a general surgeon who operates once a month on, say, bowel cancer, will have a death rate one third higher than a specialist who does three such operations a week.'

The final diagram I want to show in this section develops the relationship between quality and volume. It also links with comments I made earlier on the long duration of the study of outcomes, especially in a condition like cleft lip/palate where treatment is often required from birth to 20 years of age or more (when facial growth has ceased) to obtain optimal results (Fig. 12). It is my contention that only those units that show high quality and high volume can demonstrate further incremental improvements. In almost all branches of clinical medicine and dentistry improvements in clinical practice are made in small incremental steps, building on previous experience. We need a large number of good quality outcomes to be sure that new 'supposed improvements' actually benefit patients. Someone in a small unit might be doing good quality work, and might hit on an improved technique or diagnosis, but this can only be measured in high volume/high quality centres.

During my 25 years in Newcastle I have obviously been aware of developments in many branches of medicine as well as dentistry. To me one of the most dramatic 
improvements is in the way that paediatric oncologists now treat childhood leukaemia. I remember a consultant paediatrician giving a lecture in 1985 in the Dental School. What he said was in 1975, ie 10 years before he was speaking, he used to save children at all cost, now he saved children at least cost. In the 17 years since Professor Alan Craft (current president of the Royal College of Paediatric and Child Health) spoke those words, further developments and improvements in the treatment of childhood leukaemia and associated diseases have occurred because paediatric oncologists all over the country pool their data, and try to ensure the best treatment. Now up to $90 \%$ of leukaemia in children is curable. Here is another quote from Professor McVie. 'Survival rates for childhood cancers have more than doubled since the 1960 - more and more children have been cured every year since doctors started co-ordinating treatment and sharing best practice.'

I want to see similar improvements in survival rates for oral cancer. I believe that the dental profession has a major role to play in the prevention and early diagnosis of oral cancer and I fully support the work that Professor Peter Thomson and his colleagues are doing in putting aside professional and surgical barriers which have been so prevalent in the past and developing an integrated head and neck cancer unit. One of my reasons for asking Professor John Langdon from King's College London to give the 47th Founders' and Benefactors' Lecture, was because I knew that he had produced some of the best results for long term survival from oral cancer in the country. To move the survival rate from the 1970s to the more favourable outcome in the 1990s took 20 years' work. That is what we want to be able to see in Newcastle, real improvements for our patients. That is what clinical academics should be striving to do.

\section{CLINICAL ACADEMICS AND RESEARCH}

In a recent paper, Tomlinson and Chantler, ${ }^{11}$ the Chairman and Secretary of the Council of Heads of Medical Schools described the contribution of clinical academics:

'Clinical academics develop and provide undergraduate and postgraduate medical (dental) education. Their research informs education and training leading to improve-

\begin{tabular}{lcc}
\hline Table 4 Vacant clinical academic posts (UK). \\
\hline & Vacancies & $\%$ \\
\hline Medicine and dentistry & 391 & 11 \\
Dentistry alone & 74 & 19 \\
\hline CHMS Nuffield Trust Data 2000 & &
\end{tabular}

ments in health care. Clinical academics provide leadership in the implementation of innovation in service delivery as well as being active members of clinical teams'.

They also identified a number of pressures on the clinical academic career pathway. These included

1. Problems of recruitment and retention.

2. Anxieties about the future of clinical research.

3. Adverse effects of the Research Assessment Exercise.

4. NHS RED and SIFT.

5. Need to review contracts for clinical academics.

6. Financial disincentives to a career in clinical academic medicine.

Although they were concerned about clinical academic medicine, I believe these points are just as relevant for clinical academic dentistry.

Last year I attended a University's UK and HEFCE seminar on University and Health Care Interactions. One of the contributions was by Professor Jan Nilsson from Lund University who gave an international dimension. He reported that in Sweden, 'There is a lack of time and resources for research, research does not promote a clinical career structure and it is difficult for patient based research to compete with molecular research for funding.' Problems experienced by clinical scientists in Sweden are almost exactly the same as in this country and probably many other countries too.

Clinical academics are under enormous pressure in medicine and dentistry in Britain. The Richards Report in 1997 drew attention to the large number of vacancies for senior clinical academic posts (Senior Lecturer and above) in Britain. The Council of Heads of Medical Schools and the Nuffield Trust reported recently that there were 391 vacant clinical academic posts in the UK in 2001, 11\% of the total (Table 4). In dentistry alone, the vacancy rate was 19\% (74 vacant posts). ${ }^{12}$ Considering UK medicine and dentistry as a whole, $48 \%$ of posts are HEFCE funded, 33\% NHS funded and 19\% from other funding sources, eg industry, charity, endowments. However for dentistry alone, the proportion is skewed very much to the HEFCE source $77 \%$. The NHS contributes only $10 \%$ to the cost of clinical academic dentistry (Table 5). A further problem is the fact that NHS funding for academic posts is not evenly

Table 5 Funding sources of UK clinical academic posts in medicine and dentistry.

\begin{tabular}{lccc}
\hline \multicolumn{2}{l}{ posts in medicine and dentistry. } & & \\
\hline & HEFCE & NHS & Other \\
\hline Medicine and dentistry & 48 & 33 & 19 \\
Dentistry alone & 77 & 10 & 14 \\
(all posts per cent) & & & \\
\hline CHMS Nuffield Trust Data 2000 & & &
\end{tabular}

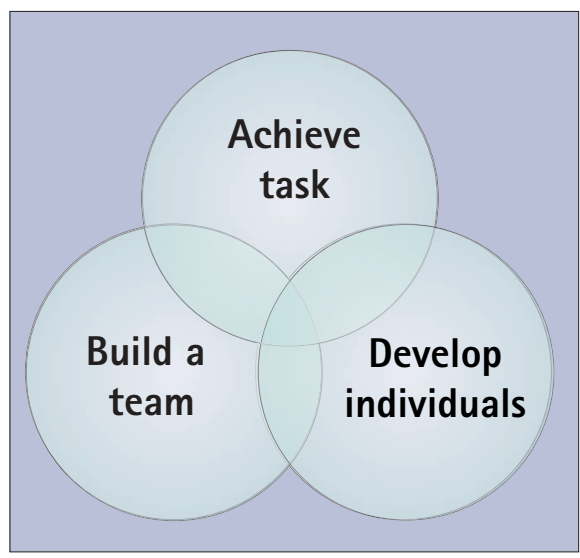

Fig. 13a) Industrial Society seminar; model for good management.

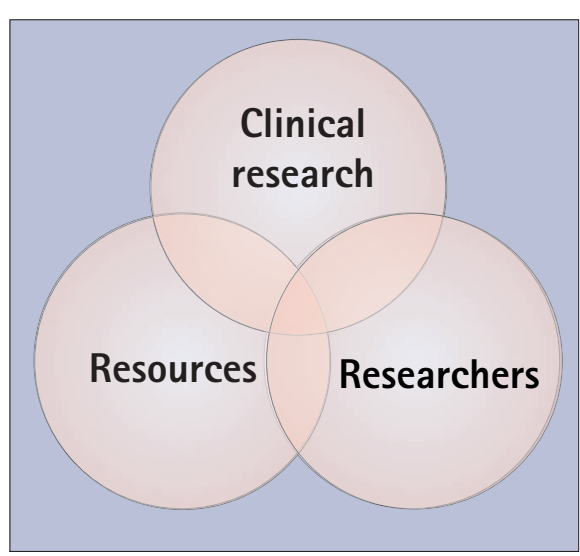

Fig. 13b) The need for resources and researchers if clinical research is to be successful.

spread throughout the country. Apparently $44 \%$ of academic posts paid for by the NHS are in London. There is no way that any provincial university with a medical or a medical and dental school can receive a fair share of resources if such an imbalance is allowed to continue.

Clinical academic medicine is in jeopardy, according to the Academy of Medical Sciences in a paper published in June $2002 .{ }^{13}$ I am a fellow of the Academy of Medical Sciences. I support all their recommendations. But the plight of clinical academics in dentistry is almost twice as bad as in clinical academic medicine.

In an article in the British Dental Journal last year I suggested that pressures on dental education were coming from at least four avenues - the challenges to universities, which all of us in academic life face, the pressures on clinical academics, medical student expansion which inevitably has brought increasing pressure on any medical faculty, and economic pressures on healthcare. ${ }^{12}$ All these issues need to be appreciated if we are to develop dental education for the next generation.

\section{RESOURCE}

I would now like to consider the physical and human resources required if clinical research is to be successful. 
About 15 years ago the University sent me on a course for Heads of Departments, organised by the Industrial Society. One of the points I remembered from the course was this diagram which it was suggested, was at the heart of good management, in any organisation (Fig 13).

I want to give two examples from my own experience. The first concerns the way the Dental School went about preparing for the Teaching Quality Assurance visitation in October 1999. The important issue was to get everyone to become involved, including students. For each of the six aspects of the assessment,

- Curriculum development

- Teaching, learning and assessment

- Student progress and achievement

- Student support and guidance

- Learning resources

- Quality management

I chose members of staff who I thought would make the best presentation. These were called 'the defenders'. Other members of staff were formed into six groups, called 'the attackers' who sought to pick holes in the dental school submission and anticipate likely questions from the visiting panel. Everyone was involved, and these discussions were carried out in a lecture theatre so any member of staff could chip in with their point of view. In the end we performed well, gaining 23 out of 24 points. We achieved the task, definitely built a team and there was no doubt that in the general discussion many colleagues showed they had 'hidden depths' and performed extremely well, as did the students, who were also involved in every section meeting.

The next example is the Research Assessment Exercise, published in 2001. We gained a 5 rating, and so were in the top four or five dental schools in the country with respect to the international quality of

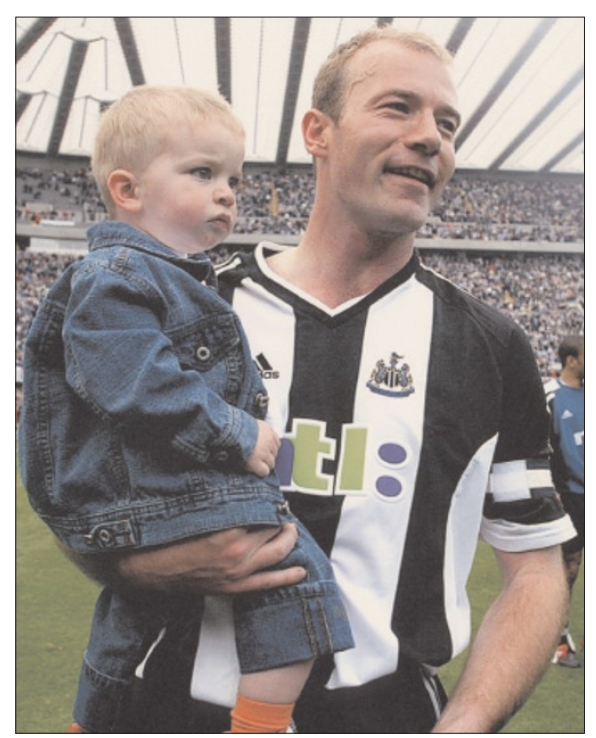

Fig. 14 Alan Shearer and his son Will, end of season St James' Park, May 2002. our research. Again we had many meetings, but this time involving smaller groups. In order to aim for a high rating we had to be selective. Some colleagues had good publications, but the research committee did not feel that their research fitted in well to the strategy that was being put forward. We did achieve the task - we exceeded the University Research Committee's expectations. We did build a team, but it was exclusive rather than inclusive, and some members of staff felt that their research effort had not been valued sufficiently. The challenge is to work with those individuals, to help them achieve a greater research profile in time for the next research assessment whenever it may be.

\section{Why have we not got a}

\section{Robson/Shearer Institute}

\section{for Orthopaedics and}

\section{Sports Medicine? We}

\section{could even have the Paul}

\section{Gascoine Head Injuries}

\section{Unit!}

You may wonder why I have decided to raise this issue in a lecture focused mainly on clinical research. Why bother to give a potted history of one hundred years of dentistry in Newcastle? The reason is that I believe that all these issues are linked. The Industrial Society pointed out the three inter-linking circles of: achieve a task, build a team, develop individuals. To prosecute clinical research we need the associate circles of physical and human resources. There is nothing wrong with looking back on 170 years of medical education, 110 years of dental education, provided we use it as a springboard to develop further. But of crucial importance is the need to attract, develop and retain staff who will contribute to our research effort in the future. The greatest satisfaction I have gained over my 36 years as an academic is seeing students, undergraduate and postgraduate, performing well, often above expectations, and appointing lecturers who develop a strong research and teaching profile and gain promotion. In the end, it is the being not the having, the person not the thing, that makes the difference in university life.

And what of Bosanquet's vision to produce one of the best medical and dental university complexes in Europe? As far as the Dental School and Hospital is concerned, I have become more and more aware, during my period as Dean of Dentistry and Clinical Director of the Dental
Hospital, of the legacy left us by Maurice Hallett and his efforts to influence the design of the Dental School and Hospital. The envelope he managed to achieve has served us well over the last 25 years, and has enabled developments to take place, in particular the re-equipping of many hospital departments, the improvements to the Oral Biology and Dental Materials Science Research Laboratories and the new Dental Clinical Skills Laboratory, which, as I indicated earlier, was funded mainly from Bradlaw's legacy. Although Bradlaw had the far greater national and international profile, I would like to suggest to you that, in terms of their impact on dental education in Newcastle, Bradlaw and Hallett stand shoulder to shoulder in the legacy they left us. But what of the wider picture of an integrated university hospital?

I am a veteran of innumerable Space Allocation Resource Committees within the Faculty of Medicine and a similar number of hospital trust meetings! Of course, I am aware of the tremendous changes in medical education, particularly in the number of medical students in Newcastle but I would venture to suggest that Bosanquet's vision has yet to be fulfilled. Perhaps the rebuilding of a major part of the Royal Victoria Infirmary, scheduled for 2006, will help to bring that initial decision in the 1950s to a successful conclusion, but it will only happen if education and health work together in a shared strategic partnership.

Perhaps some of you will have seen the photographs of Mr and Mrs Shearer with their son Will (Fig 14). Alan Shearer was perfectly happy for his wife to have their son Will in the RVI. I know how hard Professor Bill Dunlop (the current President of the Royal College of Obstetrics and Gynaecology) worked to build a unit to unify the different maternity services in Newcastle 10 - 15 years ago. His aim was to bring two essential independent units together because he believed that a department of about 5,000 deliveries a year was needed to make sure that all the sub-specialties within obstetrics and gynaecology were covered and to make services for women in Newcastle one of the most modern and progressive in the country. Mrs Shearer was right to have her baby there but, when Alan Shearer has a problem with his knee he has to go to America. We even had to send Craig Bellamy down to Leeds to have a scan. Why are these services not available in Newcastle? Why have we not got a Robson/Shearer Institute for Orthopaedics and Sports Medicine? We could even have the Paul Gascoine Head Injuries Unit! What I want for Newcastle is for every specialty to be at the leading edge of clinical development and patient care. 
OPINION

Just as Bill Dunlop strived to provide the best for women's services, my goal has been to develop dental services in Newcastle. There are only 10 dental hospitals in England. Thus the Newcastle upon Tyne Hospitals should benefit from having a concentration of talent covering all the dental specialties. Those specialties would not be in Newcastle to the same extent if there were not a dental school. As academics, our goal is to provide excellent teaching and research in the discipline of dentistry, which should bring added value to the university and the NHS.

As Chairman of the Education Committee of the General Dental Council I have been responsible for producing a framework for dental education - The First Five Years. ${ }^{14}$ I know a lot of the educational jargon involved but I have a very simple philosophy with regard to dental and medical education and it is this: medical and dental students learn best in an environment where patients are cared for and treated the best. That is the environment I want to see in Newcastle.

\section{ADULT DENTAL HEALTH SURVEY}

So, how far have we come in the last 30 years?

I qualified in 1966 and was appointed to a research fellowship at Leeds University. One of my jobs was to carry out a pilot study for the first Adult Dental Health Survey of England and Wales, which was completed in $1968 .{ }^{15}$ One of the most important findings concerned the proportion of the adult population who had no natural teeth left - they had all been extracted. Thirty seven per cent of all adults aged 16 years and over were edentulous. This overall percentage, high though it was, hid considerable regional and gender differences - London males from a social class I and II and III nonmanual background were much less likely to have lost all their teeth than working class females from the North.

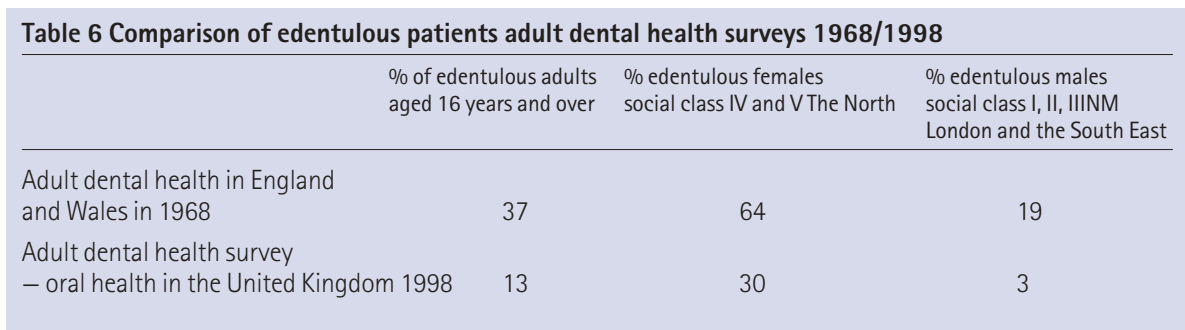

Thirty years later the 1998 adult survey was carried out with Dr Jimmy Steele and Professor June Nunn from Newcastle as coauthors. ${ }^{16}$ The prevalence of edentulousness had fallen to 13\%. There remains a considerable gap between upper class London males (3\%) and working class northern females (30\%) (Table 6). A ten fold gradient in any health indicator is totally unacceptable. One of the reasons why the figure for Northern females is so high is that many women may have been rendered edentulous at 20 or 30 years of age, and so will remain as an 'edentulous statistic' until they die. Our job as oral health practitioners is to ensure that children and young people today have the benefits of modern dentistry. Remember the pictures of the six-year-old child I showed you earlier. Although caries is not as important as cancer, it affects the majority of the population and is therefore an important public health issue.

\section{CONCLUSION}

So let me return to the title of my lecture - clinical research, second rate science or basic necessity? I would like to make three last points. Firstly, clinical research is not an optional extra or an unavoidable luxury but is a basic necessity.

Secondly I also believe that the best clinical research is as intellectually demanding, and requires just as much dedication and determination, as basic science research, but that is for you to decide.

Finally, I want you to notice something that is not there. The word dental does not feature in my title. I have sufficient confidence in my colleagues in dentistry to know that, if given a level playing field in terms of funding and opportunity, they will continue to produce high quality research, which will be of benefit to the university and the community.

1. Murray J J, Murray I D, Hill B. Newcastle Denta/School and Hospital; an illustrated history, 1895-1995. Newcastle upon Tyne: Medical Faculty, University of Newcastle upon Tyne, 1995.

2. Bettenson E M. The University of Newcastle upon Tyne: a historical introduction 1834-1971. Newcastle upon Tyne: University of Newcastle upon Tyne, 1971.

3. Burch PR J, Jackson D. Periodontal disease and dental caries. Some aetiological considerations. Br Dent J 1996: 120: 127-134

4. Moroney M J. Facts from figures. Middlesex: Penguin Books, 1965. Chapter 15, p253.

5. Sunday Times Magazine, August 2002

6. NHS Centre for reviews and dissemination Fluoridation of drinking water: a systematic review of its efficacy and safety. York: University of York, 2000.

7. Arnold FA, Likens R C, Russels A L, Scott D B. Fifteen years of the Grand Rapids fluoridation study. J Am Dent Assoc. 1962: 65: 780-785.

8. Welbury R R, Walls A W G, Murray J J, McCabe J F. The 5 year results of a clinical trial comparing a glass polyalkonate (ionomer) cement restoration with an amalgam restoration. Br Dent J 2000; 170: 177-181.

9. Welbury R R, Shaw A J, Murray J J, Gordon P W, McCabe J F. Clinical evaluation of paired compomer and glass ionomer restorations in primary molars: final results after 42 months. Br Dent J 2000; 189: 93-97.

10. Harris M, Murray J. Cleft lip and/or palate. London: HMSO 1998.

11. Tomlinson S, Chantler C. On the future of clinical academic medicine. Council of Heads of Medica Schools, internal document 2000.

12. Murray J J. Pressures on dental education - a personal view. Br Dent J 2002; 192: 433-435.

13. The Academy of Medical Sciences. Clinical academic medicine in jeopardy, recommendations for change. London: The Academy of Medical Sciences, 2002.

14. General Dental Council. The first five years: a framework for undergraduate dental education. London: Genera Dental Council. 2nd edn, 2002

15. Gray P G, Todd J E, Slack G L,Bulmam J S. Adult dental health in England and Wales in 1968. Government Social Survey. London: HMSO.

16. Walker A, Cooper I. Adult Dental Health Survey:oral health in the United Kingdom 1998. London: The Stationary Office, 2000. 